\title{
DIREITOS FUNDAMENTAIS E PESSOA COM DEFICIÊNCIA NA ORDEM CONSTITUCIONAL BRASILEIRA: UMA ABORDAGEM SISTÊMICO- AUTOPOIÉTICA
}

\section{${ }^{1}$ Flavia Piva Almeida Leite ${ }^{2}$ Mateus de Oliveira Fornasier}

\section{RESUMO}

Este artigo abordou a reconfiguração, na ordem jurídica constitucional dos direitos inseridos na Convenção dos Direitos das Pessoas com Deficiência, conforme a teoria dos sistemas autopoiéticos. A pesquisa pretende demonstrar o modo que a teoria destes sistemas pode contribuir para melhor compreender os direitos fundamentais na atual sociedade complexa. Sendo uma teoria que parte da diferença entre o homem e a sociedade, sua abordagem permite conceber que tal diferenciação é teoricamente excludente. A metodologia usada foi sistêmico-construtivista, a partir de uma abordagem bibliográfica.

Palavras-chave: Direitos fundamentais, Teoria dos sistemas autopoiéticos, Deficiência

\section{DERECHOS FUNDAMENTALES PARA LOS MINUSVALIDOS EN LA ORDEN CONSTITUCIONAL BRASILENA: UN ENFOQUE SISTEMICO-AUTOPOIETICO}

\section{RESUMEN}

Este artículo aborda la reconfiguración, la ley constitucional de los derechos consagrados en la Convención sobre los Derechos de las Personas con Discapacidad, como la teoría de los sistemas autopoiéticos. La investigación tiene como objetivo demostrar la forma en que la teoría de estos sistemas puede contribuir a una mejor comprensión de los derechos fundamentales en la compleja sociedad actual. Al ser una teoría que parte de la diferencia entre el hombre y la sociedad, su enfoque permite concebir que esa diferenciación es teóricamente exclusiva. La metodología utilizada fue sistémico- constructivista, desde una aproximación bibliográfica.

Keywords/Palabras-claves/Mots-clés: Derechos fundamentales, Teoria de los sistemas autopoieticos, Discapacidad

\footnotetext{
${ }^{1}$ Doutora em Direito do Estado pela Pontifícia Universidade Católica - PUC, São Paulo, Brasil. Professora Permanente do Programa de Mestrado em Direito da Sociedade da Informação das Faculdades Metropolitanas Unidas - FMU, Brasil. E-mail: flaviaaleite3@hotmail.com (Brasil)

${ }^{2}$ Doutor em Direito pela Universidade do Vale do Rio dos Sinos - UNISINOS, Rio Grande do Sul, Brasil. Professor da Graduação em Direito da Universidade Regional do Noroeste do Estado do Rio Grande do Sul - UNIJUI, Brasil. E-mail: mateus.fornasier@unijui.edu.br (Brasil)
} 


\section{INTRODUÇÃO}

Este trabalho, em linhas gerais, buscou abordar a elevação, na ordem jurídica brasileira, ao patamar constitucional, dos direitos elencados na Convenção Sobre os Direitos das Pessoas com Deficiência, conforme a teoria dos sistemas autopoiéticos. Nesta senda, foi conduzido pelo seguinte problema de pesquisa: de que modo a teoria dos sistemas autopoiéticos pode vir a contribuir para uma melhor compreensão dos direitos fundamentais na atual sociedade complexa, mormente no que tange à inclusão de um rol de direitos na ordem constitucional brasileira acerca das pessoas com deficiência a partir de uma Convenção internacional?

A hipótese apresentada para tal questionamento de pesquisa é de que, mesmo sendo uma teoria que parte de uma diferença entre o homem e a sociedade, sua abordagem permite conceber que tal diferenciação é teoricamente excludente (no sentido de que parte do pressuposto de que a sociedade não é formada por pessoas, mas sim, pelas comunicações operadas entre estas), mas que permite a observação de inclusões sistêmico-sociais de setores da população tradicionalmente excluídas das comunicações sociais - dentre elas, as pessoas com deficiência.

Dividiu-se este trabalho em quatro partes. A primeira delas busca definir a diferenciação teórica fundamental entre homem e sociedade conforme a teoria dos sistemas autopoiéticos, sendo deslindados preconceitos possíveis contra esta forma teórica. Assim, os fundamentos da referida teoria (sistemas, comunicação, acoplamento estrutural) são delineados, a fim de explicar as possibilidades de observação e reflexão que se abrem quando se entende o homem como acoplamento entre sistemas psíquico e biológico (e não uma unidade individual como a tradição humanista tem feito desde o advento da Modernidade). Ademais, também se busca explicar o porquê de a sociedade ser subdividida em vários outros sistemas autorreferentes, cada qual com seu sentido social diverso.

Dando-se seguimento à proposta teórica iniciada no primeiro momento textual, o trabalho se direciona à abordagem sistêmica da Constituição. Assim, Direitos Humanos e Fundamentais são "traduzidos" para o referencial da teoria dos sistemas autopoiéticos, a fim de que a análise da evolução dos direitos das pessoas com deficiência seja realizada logo posteriormente. Isto porque a grande propulsão das mudanças jusfundamentais para este segmento da população se deu justamente com uma novidade relativamente recente da Constituição de 1988 - qual seja, a inserção do parágrafo terceiro no seu artigo $5^{\circ}$, 
possibilitando que tratados que versem sobre direitos humanos sejam procedimentalmente elevados ao status constitucional.

No seu terceiro momento, direciona-se o esforço teórico para um potencial ainda pouco explorado da teoria dos sistemas autopoiéticos no que tange aos direitos humanos e fundamentais - qual seja, a possibilidade de se encarar tais direitos como includentes dos excluídos na sociedade. Em outras palavras, aponta-se para a mudança que estes causam em relação a grupos menos favorecidos (tais como as pessoas com deficiência), incluindo-os no fluxo comunicacional jurídico-social.

Por fim, observa-se mais detalhadamente a Convenção sobre direitos das pessoas com deficiência, a fim de se conceber quais são as mudanças que trazem à cultura jurídica brasileira. Vários dos seus dispositivos são, assim, estudados, a fim de se demonstrar as novas abordagens necessárias acerca de tais direitos em nossa ordem constitucional.

Adotou-se a metodologia sistêmico-construtivista, de acordo com a qual a sociedade é formada pelas comunicações dotadas dos mais variados sentidos - as quais se organizam e estruturam em sistemas autorreferentes. Assim, abordou-se o que significou a operação política (aprovação em procedimento de Emenda Constitucional) para o sistema do direito (inclusão de mais um fundamento na ordem constitucional brasileira).

\section{O HUMANO E O SOCIAL NA OBSERVAÇÃO DA SOCIEDADE (PÓS) MODERNA PELA TEORIA DOS SISTEMAS AUTOPOIÉTICOS}

A teoria da sociedade conforme concebida por Niklas Luhmann - teoria dos Sistemas autopoiéticos - detém grande potencial inovador, revolucionário (no sentido de mudança de perspectiva científica) e condutor de novas observações acerca da sociedade. Famosa por sua crítica à racionalidade (saliente-se: uma crítica não à racionalidade em si, mas à forma pela qual a racionalidade na sociedade costuma ser concebida pelas teorias sociais), considera, em todas as suas implicações, a impossibilidade de uma normatização, de uma representação e de uma racionalização totalizante da sociedade.

Esta perspectiva procura superar impasses aos quais a análise sociológica teria chegado - mormente no que concerne à incapacidade desta para descrever a sociedade altamente complexa (VILLAS BÔAS FILHO, 2009, p. 1). Trata-se de uma crise de caráter teórico (LUHMANN; DE GIORGI, 1996, p. 10), que oscila entre a análise empírica e a produção teórica incapaz de se desatrelar das visões clássicas de Durkheim, Weber, Marx, etc. (desenvolvidas em épocas e para contextos extremamente diversos dos atuais) (LUHMANN, 2010, p. 252). A teoria dos sistemas autopoiéticos busca se desfazer dos referenciais adstritos à tradição europeia, cujos conceitos se verificam como incompatíveis com a complexidade da 
realidade social hodierna. Em razão disto, propõe uma mudança de forma de observação (LUHMANN, 1998, p. 29-30), que possa tornar o estudo sociológico suficiente para o contexto social (hiper) complexo.

As várias propostas teóricas criticadas por Luhmann são oriundas da matriz (por ele denominada) concernida à "teoria da ação", a qual se caracteriza, principalmente, pela crença num continuum entre ser humano e sociedade (LUHMANN; DE GIORGI, 1996, p. 27) continuidade esta fundamentada no elemento ação, unidade mínima para a formação dos sistemas sociais, essencialmente humanas. Nesta perspectiva são concebidos sistemas sociais possíveis apenas com o concurso das ações humanas, as quais, por sua vez, seriam realizáveis pelo homem apenas no interior dos sistemas sociais. Ao assegurar a simbiose entre o humano e a sociedade, a ação, desta feita, seria o elemento último articulador entre as duas realidades (social e humana), referidas reciprocamente e vinculadas necessariamente - tornando o homem a fonte das ações, alocando-o teoricamente no centro dos sistemas sociais (VILLAS BÔAS FILHO, 2009, p. 2).

Nesta tradição humanista, o homem não apenas é entendido como condição de possibilidade para a emergência da sociedade, mas como parte integrante sua. Assim, o homem estaria tão vinculado à sociedade que apenas a partir dos requisitos normativos oriundos da ordem social seria possível implementar sua natureza plenamente - em outras palavras, a incumbência de trazer à concretude os fins humanos seria dada ao social (LUHMANN, 1990, p. 78).

Buscando superar tal tradição baseada no humano apriorístico (que veria na ação social a emanação do espírito individual na sociedade), a teoria dos sistemas autopoiéticos propõe uma nova observação do "indivíduo" - o qual, ao invés de unidade, se torna uma combinação, um acoplamento, entre os sistemas orgânico e psíquico, os quais consistiriam no ambiente dos sistemas sociais: note-se já de antemão que mesmo nesta concepção o homem também é percebido como essencial para a emergência da sociedade; porém, por ser esta ambiente do humano, este não seria seu integrante (MANSILLA, 2003, p. 124-126). Esta decisão teórica seria fundamental para a mudança de paradigma de observação da sociedade contemporânea (LUHMANN, 2007, p. 16), estabelecendo a exclusão recíproca entre sistemas psíquicos e sociais - teoria esta "herética" ou "escandalosa" para a tradição sociológica cujo principal "dogma" seria a concepção do homem como "partícula elementar" da sociedade (IZUZQUIZA OTERO, 1990, p. 73).

A teoria dos sistemas autopoiéticos exige que se assumam premissas revolucionárias da análise social (LUHMANN, 1990, p. 2) - sendo estabelecidos três níveis de análise para a distinção de diversos tipos de sistemas autorreferenciais: a) segundo a conceituação fundamental deduzida da teoria geral dos sistemas, o nível básico estaria na diferenciação 
sistema/ambiente; b) após, faz-se a distinção entre sistemas sociais (de autopoiese embasada na comunicação) e outros tipos de sistema: máquinas, organismos (de autopoiese operando sobre a base vida) e sistemas psíquicos (operando sobre a base da consciência), cada qual caracterizado por um tipo específico de autorreferência e autopoiese, o que estabelece a mútua exclusão entre indivíduo (acoplamento entre sistemas psíquico e orgânico) e sociedade, sendo que as especificidades sistêmicas de recursividade elementar as tornam fechadas, mutuamente inacessíveis; porém, por mais que consciência e comunicação se constituam de sentido, a comunicação não é capaz de "determinar o fluxo dos pensamentos de uma consciência", assim como a consciência é incapaz de "estabelecer a comunicação que circula na sociedade, a não ser por meio de irritações/perturbações" (VILLAS BÔAS FILHO, 2009, p. 5) e, c) finalmente, no terceiro nível de análise são apontados três tipos diversos de sistemas sociais baseados na comunicação, que podem ser assim categorizados: interações, organizações e sociedades.

O sentido seria o meio que permite a criação seletiva de todas as formas sociais e psíquicas, conquista evolutiva própria dos sistemas sociais e dos sistemas psíquicos que permite dar a forma à autorreferência, construção da complexidade de cada um desses sistemas, e a toda diferença sistema/entorno a eles relativa (SISTEMA SOCIAL 1996, p. 146). Articulando tanto realidade e possibilidade quanto atualidade e potencialidade, o sentido é a forma de seleção que permite a redução da complexidade característica do ambiente do sistema. Isto o alça à condição de conceito básico da sociologia, capaz de operar com a complexidade e a contingência características do mundo (LUHMANN, 1990, p. 84).

Contextualizado na teoria dos sistemas, o sentido se torna uma categoria prélinguística que: não se funda na subjetividade monológica do sujeito transcendental; simultaneamente, não se identifica com a interação mediada linguisticamente entre sujeitos que se reconhecem mutuamente e estabelecem consensualmente o entendimento acerca de algo (VILLAS BÔAS FILHO, 2009, p. 11).

Luhmann (1990, p. 27) concebe, com isto, o sentido como operação seletiva própria dos sistemas sociais e psíquicos, cuja função é regular suas relações com um ambiente cada vez mais complexo contingente - acabando com a ideia do sentido como referência de um sujeito, e passando a ser visto como redutor de complexidade do mundo por atualizar possibilidades: em razão disso o sentido fundamenta a decisão em prol de uma (possibilidade), excluindo as demais (que são preservadas como potencialidades).

Esta operação seletiva que os sistemas representam orienta a reflexão de base dos sistemas psíquicos e sociais, sendo aqui a reflexão de base entendida como operação específica realizada pelo sistema a partir de sua diferenciação frente ao ambiente (LUHMANN, 1998, p. 343). Estes fatores já são suficientes para elucidar o fato de que o 
homem (biológica ou psiquicamente compreendido, ou ainda como combinação de ambas as sistemáticas) não pode ser o elemento básico da sociedade. Quando caracterizada como sistema social, a sociedade passa a ter a comunicação como elemento último, operando somente a partir dela sua autopoiese. O homem, por sua vez, é posto no ambiente da sociedade (tanto como sistema psíquico quanto como sistema biológico/orgânico), o que, de forma alguma, não o menospreza, subordina, ou exclui da teoria social de Luhmann. Esta teoria parte justamente da diferença entre sistema e ambiente, categorias constituintes dessa diferença - e que não são, de forma alguma, hierárquica ou valorativamente posicionadas: ambiente e sistema são extrema e simultaneamente importantes para a teoria.

Tornar o ser humano ambiente (entorno) da sociedade não significa relegá-lo a um nível inferior de importância, visto não haver juízos de valor ou concepção ontológica nesta operação - a qual é apenas um desdobramento lógico da autorreferência característica dos sistemas. É em virtude da premissa da diferenciação sistema/entorno entre homem e sociedade que a teoria dos sistemas autopoiéticos demanda definições precisas do tipo específico de operação necessária para a emergência de um sistema (VILLAS BÔAS FILHO, 2009, p. 14): um sistema só se reproduz mediante uma forma específica de operação (e não de uma amálgama de elementos variados, e. g. físicos, biológicos, psíquicos e comunicacionais). São excluídas, com isto, as abordagens normativas e seus problemas de fundamentação da análise social - o que é teoricamente vantajoso quando se compara esta abordagem com aquelas concepções que têm o homem (e sua ação) como núcleo da sociedade.

Assim, dada a separação analítica entre sistema psíquico (uma das "facetas" do "homem") e sistema social, não é mais necessário analisar a sociedade como sendo o local de realização das aspirações que seriam próprias do domínio do ser humano: este tipo de visão seria altamente questionável e atrelada a visões de mundo e preconceitos que apenas servem para obnubilar a análise social (LUHMANN, 2010, p. 261-262). Percebe-se quão frutíferas podem ser as análises dos prováveis efeitos do desenvolvimento social (e.g. jurídico, político, científico, etc.) nos processos e seres "naturais", mas também no próprio corpo e no próprio espírito do homem (ou seja, as irritações sociedade/sistema biológico humano, bem como sociedade/sistema psíquico humano).

Não obstante serem componentes do ambiente, os sistemas biológicos e psíquicos são indispensáveis para a emergência da comunicação, operação constitutiva da autopoiese dos sistemas sociais. O importante é se ressaltar a falibilidade da combinação teórica acriteriosa das instâncias psíquicas, orgânicas e sociais diluiria num todo confuso a autorreferencialidade dos vários tipos de sistema que não são mútua e causalmente interrelacionados (sendo transmutada a autorreferência em heterorreferência). Ademais, apesar de serem autorreferentes, os sistemas (dos mais variados tipos) não são absolutamente apartados, 
já que (LUHMANN, 2007, p. 72-79): a) não há causalidade subdeterminante e subjacente entre sistemas; b) porém, há ligações entre os sistemas, as quais se dão mediante operações altamente seletivas, que tornam possível a inter-relação intersistêmica; c) além disso, os diversos sistemas podem se acoplar estruturalmente (e.g. o acoplamento entre sistemas psíquicos e sociais ocorrente mediante a linguagem) e se interpenetrarem.

A teoria dos sistemas autopoiéticos considera que o elemento básico a ser observado na sociedade é a comunicação, sendo os indivíduos sistemas autopoiéticos diversos, cujo elemento básico é a consciência - o que os torna ambientes uns dos outros de maneira recíproca. Com isso, queda-se o homem colocado no exterior da sociedade, o que impede que esta última se traduza “[...] como uma antonomásia das aspirações humanas” (VILLAS BÔAS FILHO, 2009, p. 90).

Esta separação analítica (homem-sistema psíquico/sociedade-sistema social) representa uma verdadeira mudança de paradigma: a sociedade passa a ser estruturada como um sistema autopoiético autorreferencial, operacionalmente fechado e diferenciado do seu ambiente, e que compreende no seu interior todas as comunicações. Em decorrência desta multiplicidade comunicativa, o sistema social se subdivide em subsistemas funcionais distintos, os quais produzem comunicações condicionadas por restrições mais limitadas - que se adstringem aos códigos binários específicos de cada subsistema. Nesta linha de raciocínio, tomados individual e distintamente, o Direito, a Política, a Economia, a Educação, a Religião, a Arte, a Ciência, etc., representariam cada um, por si só, um subsistema que, por questões da própria lógica, não podem ingerir diretamente sobre os demais (LUHMANN, 1990, p. 236).

As sociedades modernas, estruturadas a partir da diferenciação funcional, se diferenciam em subsistemas funcionais autopoiéticos e autorreferenciais, em que o critério fundamental para a construção do sistema não é mais a posição (hierárquica) de cada estrato social (como ocorria em sociedades pré-modernas), mas a função desempenhada por cada subsistema na sociedade. Com isso, cada subsistema funcional realiza uma função específica a partir de uma estrutura baseada num código binário próprio e exclusivo. Assim, cada um destes subsistemas só pode observar a sociedade a partir de sua própria função - fator que oblitera qualquer possibilidade de um subsistema específico intentar a postulação de prerrogativas (arrogar-se posição privilegiada) sobre quaisquer outros. Observar é produzir informação; esta, por sua vez, se liga à comunicação. A interpretação jurídica está interrelacionada com a observação do Direito. Por conseguinte, a fim de se produzir uma observação diferenciada, deve-se ter poder - cuja principal característica é ser um meio comunicativo que produz, controla e processa as informações (LUHMANN, 1985, p. 5-17). Tem-se, assim, que a observação pode estabelecer critérios para a constituição de uma teoria do Direito - a qual, por sua vez, elaboraria uma observação reflexiva sobre a totalidade da 
comunicação de sentido jurídico (ROCHA, 2013, p. 42). E, conforme a teoria que se adota, varia o ponto de vista da observação - sendo que uma observação diferenciada exige o uso de matrizes teóricas diferentes das tradicionais.

A teoria dos sistemas autopoiéticos se vale, de várias maneiras, de contribuições das ciências cognitivas, da informática e da nova lógica, que ocasionaram a ênfase em seus aspectos dinâmicos.

A matriz pragmático-sistêmica luhmanniana provoca grande mudança epistemológica na teoria do Direito - e, talvez por isso, não influenciou significativamente a dogmática positivista dominante (ROCHA, 2013, p. 30). Seu ponto de partida se deu com as análises de Parsons sobre os sistemas - mas, em seus últimos textos, o sociólogo de Bielefeld se volta para a perspectiva epistemológica autopoiética de Maturana e Varela, acentuando que o Direito é um sistema autorreprodutor, tendo, assim, rompido com o funcionalismo parsoniano (de modelo input/output).

Com a pespectiva pragmático-sistêmica autopoiética pode-se afirmar que, por trás das dimensões da semiótica (sintaxe e semântica), as funções pragmáticas da linguagem estão presentes no processo de tomada de decisão jurídica, redefinidas no interior do sistema, redefinido, dessa maneira, as questões do paradoxo e do risco. É por isso que se pode afirmar que Luhmann avança para muito além de Kelsen (analítica) e de Hart (hermenêutica), tendo definido o Direito como sendo uma estrutura de generalização congruente em três níveis: temporal (normal), social (institucionalização) e prático/objetivo (núcleo significativo) (LUHMANN, 1983, p. 116). O comportamento social em um mundo altamente complexo e contingente, na sociologia do Direito luhmanniana, exige gradações que possibilitem expectativas comportamentais recíprocas, orientadas a partir de expectativas acerca de tais expectativas, sejam realizadas.

Assim, o mundo social caracterizado pela complexidade e pela contingência requer reduções que possibilitem expectativas comportamentais recíprocas orientadas a partir das expectativas sobre tais expectativas. Isto depende da harmonização das dimensões, pela via da redução que se dará em cada uma delas, mediante mecanismos próprios. Tal harmonização/redução é denominada "generalização congruente" (coerente) (LUHMANN, 1983, p. 109).

O Direito, para Luhmann, não é um ordenamento primariamente caracterizado pela coação; na verdade, é um alívio, uma estabilização das expectativas. A função do Direito é, portanto, a seleção das expectativas comportamentais que possam ser generalizadas em todas as dimensões (temporal, social e prática). Mas, por mais que seja uma estrutura, é visto como dinâmico, em virtude da permanente evolução decorrente de sua necessidade de agir constantemente como uma das estruturas sociais redutoras da complexidade das 
possibilidades de ser no mundo.

A teoria dos sistemas conforme a visão luhmanniana proporciona a configuração de um "novo estilo científico", mais capacitado para compreender as atuais sociedades complexas - ao contrário dos limitados modelos de sociedade que o normativismo, a hermenêutica e a pragmática jurídicas desenvolveram (ROCHA, 1999, p. 130). A complexidade heterogênea causada pela dupla contingência é detida pelos processos de identificação estrutural - que são possibilitados apenas com a criação de diferenciações funcionais. Tem-se, com isso, que a teoria sistêmica do Direito comunica a norma jurídica com o social e a prática significativa, dando um importante passo para a construção de uma nova teoria do Direito, que aborde seus aspectos analíticos, hermenêuticos e pragmáticos em relação ao sistema social.

Muito importante para a continuidade do tema que ora se propõe - qual seja, a evolução recente do sentido jurídico dos direitos fundamentais das pessoas com deficiência pelo Direito e pela Política na ordem jurídica brasileira, após a irritação realizada pela ordem jurídica internacional - é entender o papel da Constituição na teoria dos sistemas autopoiéticos. Dado que as alterações normativas recentes neste sentido - em especial, a submissão (e aprovação) da Convenção internacional que versa sobre os direitos das pessoas com deficiência ao procedimento de Emenda, elevando-a a norma de caráter constitucional são verdadeiramente revolucionárias teoricamente, deve-se entender o que a teoria dos sistemas autopoiéticos entende por Constituição, Direitos Humanos e Fundamentais.

\section{A ABORDAGEM SISTÊMICA DA CONSTITUIÇÃO}

Observa-se nas Constituições que o paradoxo da diferença entre Direito e Política passa a não mais ser resolvido pela hierarquia entre direito divino, natural e positivo (que servira para a afirmação da soberania absoluta ao Estado), mas mediante a afirmação definitiva da positividade do Direito: "o Direito positivo bifurca-se em direito intangível e direito disponível” (LUHMANN, 1991, p. 41). Assim, tanto para o subsistema parcial comunicativo político quanto para o jurídico, a Constituição surge como nova modalidade de diferenciação nas operações internas do sistema, entre a auto e a heterorreferência (LUHMANN, 1996b).

A partir do ponto de vista jurídico, a Constituição seria o substituto funcional do Direito Natural, pois o “positiva”. Já do ponto de vista político, seria o local onde o poder absoluto do monarca é substituído pelo reconhecimento dos direitos dos cidadãos como sendo limitação para o exercício do poder político. Assim, ela cria e limita, paradoxalmente, liberdades consentidas a ambos os sistemas. E, com isto, surge a diferença entre direitos 
humanos e direitos fundamentais, sendo que, nos idos do séc. XVIII, estes segundos assumem o significado de "direitos de liberdade positivados em uma ordem jurídico-política concreta, isto é, em um determinado Estado", enquanto os direitos humanos se tornam direitos inerentes ao próprio poder advindo da condição de pessoa (MAGALHÃES, 2008, p. 41).

Apresentam-se, na diferença entre direitos humanos e fundamentais, pois, dois critérios quando do advento da ideia moderna de Constituição: um territorial (direitos fundamentais seriam reconhecidos no interior de uma determinada ordem estatal); e um temporal - ao serem fundados constitucionalmente os direitos fundamentais na sua projeção para o futuro, apresenta-se a possibilidade de sua efetivação no presente.

Verifica-se que as Constituições, na modernidade, significaram a unidade da diferença (ainda que precária e artificialmente) entre os sistemas do Direito e da Política, tendo sido o instrumental que impediu o fechamento da Política e do Direito em si próprios: um limita o outro, ao mesmo tempo em que ambos são livres para realizarem suas operações (até o limite do outro); contudo, cada um de ambos é autorreferente a operacionalmente fechado (apesar de cognitivamente aberto) (MAGALHÃES, 2008, p. 43-44).

Nas condições da sociedade moderna, entretanto, estando os Direitos Humanos a serem visualizados a partir dessa dupla perspectiva (fundamental, para o Direito; instrumental, para a Política), não se tornam capazes de integrar ambos os sistemas - e isto não apenas em decorrência do conflito igualdade/liberdade (ou soberania popular/direitos humanos): esta não convergência provém da própria diferenciação funcional, que coloca a cada sistema a função de resolver diferentes problemáticas sociais (e os direitos humanos passam a ser interpretados de diferentes maneiras por cada um deles). Aliás, aí residiria, também, a problemática do caráter puramente (ou muito mais) simbólico dos Direitos Humanos em diversas situações em que não se verificaria a sua efetivação: em muitas das regiões onde isto se daria, provavelmente o Direito não tenha se fechado operativamente a ponto de se tornar impermeável à influência do(s) código(s) de outro(s) sistema(s) social(is).

Em razão da diferenciação Direito/Política, no que tange aos Direitos Humanos, novamente emerge o caráter paradoxal destes - sendo que, para que sobrevivam às Constituições e à "crise da soberania", novos fundamentos devem ser encontrados para eles: tanto a ideia de direitos naturais quanto a de fundamentalização mediante a positivação constitucional quedam-se insuficientes no atual contexto (mundializado ou, conforme a linguagem mais comumente utilizada, "globalizado"), tornando-se frequente falar-se num cosmopolitismo embasado na ideia de Direitos Humanos. Exsurge, assim, o discurso da desvinculação das referências territoriais, jurídicas e políticas estatais, vislumbrando-se que a expectativa ao redor dos Direitos Humanos é de que eles transcendam as fronteiras dos Estados, do poder e do direito estabelecido. (MAGALHÃES, 2008, p. 46). 
É particularmente em razão disto que é possível afirmar que os Direitos Humanos, ao ser esvaziada a possibilidade de serem encarados como realidades (ontológicas), são ficções capazes de produzir realidades - ou seja, embora sejam paradoxais em sua natureza, são capazes de se desenvolverem operativamente (MAGALHÃES, 2008, p. 47). A realidade mostra, assim, que mais relevante do que buscar os fundamentos dos Direitos Humanos ou identificar quais são as promessas não cumpridas feitas em seu nome, deve-se observar seriamente o que é efetivamente produzido conforme sua lógica.

\section{DIREITOS FUNDAMENTAIS E A INCLUSÃO DOS EXCLUÍDOS: DA MUDANÇA DE PARADIGMA NA CULTURA JURÍDICA COM A CONSTITUCIONALIZAÇÃO DOS DIREITOS DAS PESSOAS COM DEFICIÊNCIA}

Ao se trazer a observação dos Direitos Humanos como sendo constitutivos de um manancial de significação para a práxis dos sistemas internos, estatais, do Direito; ao se observar decisões tomadas e teorias desenvolvidas por outras ordens jurídicas (estatais, internacionais, etc.) como modelo a ser reavaliado no diálogo entre ordens, e não como mero transplante de material alienígena; ao se reconsiderar a própria policontextualidade e a hipercomplexidade normativas como características das possibilidades de comunicação, em que se podem visualizar catálises provocativo-transformativas do sentido jurídico das mais variadas ordens; estar-se-á diante de uma forma de observação de um Direito complexo para uma sociedade complexificada pelas transformações causadas no ambiente social pelos mais variados sistemas.

Seria mais coerente em relação ao atual estado de coisas, dessa forma, abandonar a ideia de fundamentação dos Direitos Humanos em uma semântica ultrapassada da moralidade, em prol daquilo que Luhmann (1996a, p. 466) denomina "danos da verdade": uma sociedade altamente complexa, no qual o caráter científico passa a influenciar cada vez mais âmbitos sociais (e inclusive o Direito), não pode deixar de atribuir importância ao aspecto cognitivo das comunicações que estabeleçam pretensas verdades (exceto, por óbvio, quando a possibilidade de falseabilidade de tais comunicações ainda esteja por demais presente).

Assim, mais profícuo do que remontar a ideia de Constituição a uma moralização decorrente de uma tradição histórica correlata ao advento da modernidade apenas ("nascimento" do Estado-nação), é ter em sua ideia a possibilidade comunicativa de efetivação dos direitos que ela positiva mediante a identificação de sua semântica à pragmática nela contida, acoplando-a estruturalmente a outros sistemas sociais (Política, Economia, etc.).

Não há uma unidade autopoiética que contenha todos os sistemas constitutivos 
humanos (psíquico, biológico e comunicativo) - mas isto não significa que o humano não exista: tal raciocínio apenas afasta a possibilidade de configuração absoluta de um antropocentrismo em nível de teoria sociológica (LUHMANN, 1996a, p. 226). Com isto, temse que o essencial não é definir o que é o ser humano para os Direitos Humanos, mas sim, em conceber o sentido do humano na comunicação específica estabelecido pelo sistema do Direito - pois nenhum dos sistemas que se acoplam para constituir o humano o representa integralmente, sendo necessário conceber os três (corpo, psique, representação social) como importantes para a sua configuração.

O uso da expressão "Direitos Humanos", geralmente, faz referência a noções surgidas no contexto das revoluções liberais, e que se combinava ao conceito de cidadania. Mas o desenvolvimento das ideias acerca de Direitos Humanos passa a ser desenvolvida também com as dimensões política (participar da escolha acerca do governo, em geral) e social (direitos, em stricto sensu, prestacionais a serem atendidos pelo Estado) - para além da ideia original, de liberdades negativas em relação ao Estado.

A abordagem sistêmica acerca da matéria demonstra o esforço em se realizarem distinções entre ambas as categorias. Os direitos fundamentais (constitucionalmente positivados), assim, teriam a função de manter uma ordem diferenciada de comunicação (reagindo, assim, ao "perigo da desdiferenciação") (LUHMANN, 2010, p. 98-99). Apesar de, em suas primeiras obras, ter desprezado a noção de direitos humanos por considerá-los “eternos", Luhmann (2010, p. 99) posteriormente enfatizou que "entre os mais importantes indicadores de um Sistema jurídico global está a crescente atenção dada à violação de direitos humanos" (LUHMANN, 2004, p. 482). ${ }^{1}$

Sistemicamente, os Direitos Humanos guardam relação direta com o problema da exclusão - o que demonstraria sua orientação para a inclusão do homem como pessoa nos sistemas sociais funcionais (especialmente no Direito) (LUHMANN, 2004, p. 490). Ou seja: o fato de alguém não ser comunicado sobre si em um sistema já é uma violação aos Direitos Humanos - cujo papel é, justamente, criar condições, no programa sistêmico, para que determinadas pessoas, categorias e grupos de excluídos tenham reconhecida a sua condição/situação e, a partir de tal reconhecimento, gozar de direitos que os coloquem em pé de igualdade de condições para com os demais.

Contudo, em Luhmann é notável uma semântica restritiva dos Direitos Humanos, nela incluindo apenas situações de violação extrema à dignidade humana na sociedade mundial, tais como o desaparecimento (assegurado pelo Estado) de pessoas, expulsões e deportações forçadas, prisão, tortura e mortes contrárias ao Direito (com proteção e conhecimento de órgãos estatais) (LUHMANN, 2004, p. 485-486).

Esta restrição dos Direitos Humanos apenas aos âmbitos em que se considera a 
ofensa à pessoa pelos abusos estatais não parece justificável para Neves (2009, p. 252), o qual versa que, para além das violações extremas aos direitos humanos avalizadas (de uma forma ou outra) pelo Estado, também deve ser entendida como violação a mácula aos chamados direitos humanos de terceira geração, que são fragilmente institucionalizados, e as perspectivas de sua positivação e implementação processual em extensão mundial são negativas.

A interessante proposta do autor brasileiro é de que se definam primariamente os Direitos Humanos como sendo expectativas normativas destinadas à inclusão de todos os seres humanos na sociedade mundial - delineando-se como o acesso universal ao subsistema social do Direito (NEVES, 2005, p. 8-10). Este raciocínio acerca de tais direitos não se

1 Tradução nossa. Texto original: "Among the most important indicators of a global legal system is the increasing attention paid to the violation of human rights".

chocaria com a mais atual das concepções luhmannianas recém apresentadas, pois continua a ser sustentado que os Direitos Humanos reagem ao perigo da desdiferenciação.

A diferença entre as nomenclaturas (humanos ou fundamentais) residiria, assim, apenas no seu âmbito de pretensão de validade: enquanto os Direitos Humanos pretendem validade para o sistema jurídico mundial de múltiplos níveis (qualquer ordem jurídica da sociedade mundial, não apenas a ordem internacional), os fundamentais são válidos dentro de uma ordem constitucional determinada de um Estado (NEVES, 2009, p. 253-254).

Por mais que tanto Direitos Humanos quanto Fundamentais se destinem à inclusão do excluído, a dogmática jurídica ainda supervaloriza a distinção de âmbitos de validade entre ambos. E esta supervalorização - relacionada à cultura jurídica, ou seja, ao seu programa e ao modo de operá-lo - é respondida com novas operações pelo sistema, a partir deste próprio programa (quando este apresenta condições para fazê-lo). É nesta senda que a submissão (e aprovação) da Convenção sobre Direitos das Pessoas com Deficiência foi operacionalizada reconhecendo-se, inicialmente, a diferença entre Direitos Humanos (positivados na Convenção) e Fundamentais (reconhecidos como constitucionais na ordem brasileira). Contudo, trata-se de um exemplo bem sucedido, no sentido pragmático, eis que a Política tem reconhecido a condição da pessoa com deficiência como sendo notável para suas comunicações (na forma de procedimentos de Emenda, bem como na promulgação de um Estatuto da Pessoa com Deficiência). Ademais, a comunicação política, em uma ordem de tradição Romano-Germânica (como a brasileira), estes novos diplomas normativos criam condições de possibilidade para a evolução do modo de decisão no sistema jurídico.

A sociedade sempre conviveu com a existência de pessoas com deficiência. Trata-se 
de uma contingência física e biológica plausível (seja de modo congênito, seja de modo adquirido). Contudo, a sobrevivência do portador de deficiência sempre significou uma luta contra a exclusão - perpetrada por vários sistemas sociais - seja pela Política, que sequer os considerava ao promulgar leis; seja pelo Direito que, em sua dogmática legalista, sequer considerava a possibilidade da afirmação da diferença com vistas à obtenção de direitos de igualdade.

Somente a partir de 1980, a Assembléia Geral da ONU passa a aprovar resoluções com o intuito de derrubar a prática da exclusão social a que foram submetidas, por vários séculos, as pessoas com deficiência, começando a inseri-las nos sistemas sociais como a educação, o trabalho, a família e o lazer. Cabe relembrar que, nessa época, a visão ou modelo médico passa a dominar o entendimento das pessoas com deficiência. Por esse modelo, a deficiência era vista como uma doença que devia ser tratada e, após isso, a pessoa estaria incluída, podendo assim ocupar o seu devido lugar na sociedade. Verificamos que esse modelo mostrou-se insuficiente para acabar com a discriminação, como também pouco eficiente para propiciar a verdadeira igualdade de oportunidades a essas pessoas no âmbito social.

O modelo médico foi tão marcante que influenciou fortemente o discurso dos próprios defensores da causa das pessoas deficientes, bem como o conceito do que vem a ser pessoa com deficiência incorporada pelas leis brasileiras. ${ }^{2}$

Considerando que somente no ano de 1993 a Assembléia Geral da ONU adotou o documento sobre a Equiparação de Oportunidades para as Pessoas com Deficiência (Resolução 44170) e que em todas as suas definições estava implícito o princípio da igualdade de direitos, deu-se início o movimento de inclusão social que, inspirada pelos princípios da celebração de diferenças, do direito de pertencer, da valorização da diversidade humana, da solidariedade humanitária, da igual importância das minorias e cidadania com qualidade de vida, demandará a construção de um novo tipo de sociedade: uma sociedade mais democrática, mais tolerante e mais inclusiva.

O Brasil não destoou dessa evolução que já se vinha operando no mundo todo. Com exceção do princípio formal da igualdade, que estava presente nas Constituições Brasileiras, alguma preocupação com esse grupo de pessoas podia ser vislumbrada nas Constituições de 1934, 1937 e 1946. Todavia, foi somente a Constituição Federal de 1967 que pela primeira vez fez menção explícita da condição de pessoas com deficiência, tratando-se das pessoas com deficiência mental que recebia a expressão "excepcional". 3

No entanto, o maior avanço de então se deu com a Emenda Constitucional $\left.n^{\circ} 12\right\lrcorner 78$, que cuidou de assegurar a essas pessoas, de forma expressa, a melhoria de suas condições sociais e econômicas, especialmente mediante educação especial e gratuita, à assistência, 
reabilitação e sua reinserção, à proibição de discriminação, bem como à possibilidade de acesso aos edifícios e logradouros públicos.

Percebe-se que a acessibilidade a edifícios e logradouros públicos já era assegurada nessa ocasião. ${ }^{4}$ Nesse mesmo sentido, a Emenda $n^{\circ} 12$, hoje, certamente, seria objeto de

2 As definições do que vem a ser pessoa com deficiência trazida pelo Decreto ${ }^{\circ}{ }^{5} 5.296 / 04$, o da Convenção da Guatemala que incorporou ao sistema legislativo brasileiro pelo Decreto $\mathrm{n}^{\circ} 3.956 / 01$, bem como o proposto pelo Estatuto da Pessoa com Deficiência basearam-se em critérios médicos, sendo a divisão feita em deficiência física, sensorial (visual e auditiva) e mental.

3 Na Constituição de 1967: “Art. 175 - A família é constituída pelo casamento e terá direito à proteção dos poderes públicos (...) $\S 4^{\circ}$ - Lei especial sobre a assistência à maternidade, infância e à adolescência e sobre a educação de excepcionais".

4 Dizia a precitada Emenda 12, à Constituição Federal de 1967 promulgada em 17 de outubro de 1978: "Artigo único. É assegurada aos deficientes a melhoria de sua condição social e econômica especialmente mediante: I

severas críticas se tivéssemos em mente o quadro atual da evolução, que combate fortemente o ensino segregado a essas pessoas, bem como a utilização da expressão deficiente. No entanto, para 1978 o avanço foi grande.

Foi somente com a Constituição Federal de 1988 que o tratamento da pessoa com deficiência se modifica, passando a um enfoque muito mais preocupado com a inclusão social. Já em seu preâmbulo, anunciou-se o propósito de construir um Estado Democrático pautado em uma sociedade fraterna, pluralista e sem preconceitos, onde esteja assegurada a igualdade, dentre os fundamentos que alicerçam o Estado Democrático de Direito brasileiro. Elencou, em seu artigo $1^{\circ}$, III, a dignidade da pessoa humana como fundamento desse novo Estado. Consagrou em seu artigo $3^{\circ}$ e incisos os objetivos fundamentais a serem perseguidos. Determinou a prevalência dos direitos humanos dentre os princípios a reger suas relações internacionais com os demais países (artigo 4, II). E, no caput e no $\$ 1^{\circ}$ do seu artigo $5^{\circ}$, assegurou o princípio da igualdade, que passa a ser considerado dentro desse novo enfoque introduzido pela Lei Maior, como o valor mais alto dos direitos fundamentais, funcionando como regra mestra de toda a hermenêutica constitucional e infraconstitucional.

A mais caracterizadora dessa proteção é a acessibilidade às pessoas com deficiência, assegurada, não de forma genérica, mas, expressamente no artigo 227, parágrafo segundo e, no artigo 244.

A luta pela inclusão dessas pessoas em todos os seguimentos da sociedade teve sequência. A Organização das Nações Unidas, preocupada com as sucessivas violações dos direitos humanos das pessoas com deficiência no mundo inteiro, conclui que esse grupo demandava uma atitude institucional da comunidade internacional, e, em 30 de março de 2007, em sua sede em Nova Iorque, assina a Convenção sobre os Direitos das Pessoas com Deficiência e o seu Protocolo Facultativo.

Cabe esclarecer que a Convenção sobre os Direitos das Pessoas com Deficiência e 
seu Protocolo Facultativo passam a ser o primeiro Tratado Internacional a ingressar na nossa ordem jurídica interna com status de equivalência constitucional, por ter sido aprovado nos exatos termos da regra imposta pelo $\S 3^{\circ}$ do artigo $5^{\circ}$ da Constituição Federal. A finalidade dessa Convenção não foi apenas a de instituir novos direitos humanos e liberdades fundamentais para as pessoas com deficiência, mas em garantir que essas pessoas possam vir a desfrutá-los em igualdade de condições com todos os demais direitos, sem discriminação. E

- educação especial e gratuita; II - assistência, reabilitação e reinserção na vida econômica e social do País; III - proibição de discriminação inclusive quanto à admissão ao trabalho ou ao serviço público e a salários; IV-possibilidade de acesso a edifícios e logradouros públicos"' (g.n.)

para que isso ocorra, reforça a ideia de que as barreiras, e em nosso estudo, as barreiras físicas, impedirão a possibilidade dessas pessoas de usufruírem de seus direitos em condições de igualdade.

Nota-se, nesta inclusão constitucional, a possibilidade de observação política dos direitos fundamentais de modo instrumental pela política, mas ao mesmo tempo, do seu papel fundamentador do ponto de vista do programa jurídico. A emenda que eleva os direitos elencados na Convenção sobre pessoa com deficiência ao status constitucional no Brasil passa a representar não apenas um item numa estrutura escalonada de normas, mas sim, um fundamento argumentativo a ser utilizado pelo sistema do Direito. Ademais, pelo sistema da Política, se instrumentaliza como fundamento para as comunicações políticas a serem realizadas com intuito normatizador.

É nesta senda que se pode afirmar que a promulgação da Lei $\mathrm{n}^{\circ} 13.146$, de 06 de julho de 2015 (Estatuto da Pessoa com Deficiência) é verdadeira representação da instrumentalização da Constituição (entendida como ordenamento constitucional, e não apenas como texto original denominado Constituição) pelo sistema da Política (já que uma Lei, no caso brasileiro, é resultado de comunicações políticas).

A principal contribuição da Convenção (e do Estatuto da Pessoa com Deficiência) é a positivação da mudança de paradigma da visão jurídica da deficiência, que passa do modelo médico (deficiência como problema de saúde) para o modelo social dos direitos humanos deficiência como resultante de uma equação que tem duas variáveis, quais sejam: a) limitações funcionais do corpo humano; b) presença de barreiras físicas impostas pelo ambiente.

A Convenção, ao reconhecer o modelo social como o mais novo paradigma para conceituar as pessoas com deficiência, embasa também a consolidação da acessibilidade tanto como princípio, quanto como um direito. E como princípio-direito obriga os Estados à sua implementação como garantia fundamental, extremamente relevante para a concretização dos 
direitos humanos das pessoas com deficiência.

A acessibilidade se constituiu num direito instrumental, afinal, sem acesso aos equipamentos urbanos, às escolas, aos postos de saúde, aos transportes públicos, as pessoas com deficiência não podem exercer, plenamente, a sua cidadania. Não há o exercício da inclusão social sem acessibilidade.

A presença da acessibilidade no meio urbano, bem como nas edificações, nos transportes e nas suas mútuas interações é uma exigência constitucional. Surge, atualmente, de acordo com a Convenção sobre o Direito das Pessoas com Deficiência, como um direito forte, o que impacta na concepção contemporânea dos direitos humanos e impõe sua releitura, sob essa nova perspectiva.

Para que seja uma realidade a efetivação do direito à acessibilidade, prossegue a Convenção determinando que os obstáculos e barreiras existentes em edifícios, rodovias, meios de transporte e outras instalações internas e externas, inclusive escolas, residências, instalações médicas e locais de trabalho, bem como, informações, comunicações e outros serviços, inclusive serviços eletrônicos e de emergência, deverão ser identificados e eliminados.

Assim, a acessibilidade é uma condição de aproximação, com segurança e autonomia, a determinados espaços, objetos e elementos diversos, possibilitando a utilização de todas as atividades inerentes e usos específicos que eles possam oferecer. Como se percebe a pessoa com deficiência só conseguirá usufruir de seus direitos se tiver um espaço que esteja acessível, isto é, um ambiente em que a pessoa com deficiência consiga se locomover, se deslocar livremente pelos seus espaços. Sair de sua residência, encontrar pelo seu caminho uma calçada que esteja com o piso adequado; as esquinas com rampas; transporte adaptado etc.

\section{CONSIDERAÇÕES FINAIS}

Após todo o exposto anteriormente, cabem algumas considerações a título de encerramento do presente trabalho. Inicialmente, é de se salientar que, apesar de a teoria dos sistemas autopoiéticos não ser uma teoria humanista (e/ou individualista), trata-se de uma possibilidade muito profícua de observação sociológica do humano em sociedade. Isto porque, apesar de partir da diferença (e não da igualdade) social, não significa que tal diferença seja valorativa, mas apenas analítica, observacional. A diferença a ser estabelecida é entre sistema e ambiente, sistemas biológicos, psíquicos e sociais. Esta diferença faz com que se exclua da teoria da sociedade o humano como unidade, mas que o mesmo seja analiticamente cindido em psíquico e biológico, interagindo na sociedade pela via da linguagem. 
Dentre os vários sistemas sociais (embasados na comunicação), emergem aqueles de sentido jurídico (Direito) e de sentido político (Política), dentre vários outros. Cada qual é autopoiético, autoconstruído e autorreferente - ou seja, reproduz-se no tempo e no espaço de acordo com seus próprios parâmetros. Mas, apesar desse fechamento (operativo), há acoplamentos entre tais sistemas. Mormente no que tange à Política e ao Direito, seu mais significativo acoplamento é a Constituição - a qual serve de base tanto para um sistema quanto para outro (cada qual, obviamente, dotando-a de um sentido diverso). No Caso do Direito, os direitos identificáveis numa Constituição são tidos como fundamentais. Já no caso da Política, as mesmas comunicações são dotadas de sentido limitador e instrumental ao mesmo tempo - em outras palavras, o que é comunicado no programa constitucional é observado, pelo sistema da Política, como rol de instrumentos para concretização.

Ao se perceber esta diferença entre comunicação jurídica e comunicação política acerca da Constituição, aliada à renovação da observação do humano em sociedade, pode-se identificar os direitos fundamentais não apenas como direitos humanos incluídos em uma ordem constitucional em específico. Tal compreensão continua tendo valor dogmático específico para a compreensão do jurídico - mas, após sua reconfiguração a partir da teoria dos sistemas autopoiéticos, pode-se entender que tanto direitos humanos quanto fundamentais podem ser socialmente entendidos como direitos destinados à inclusão (ou seja, a um comunicar sobre) daqueles que se encontram excluídos dos sistemas (ou seja, acerca daqueles sobre os quais não se comunica).

A não comunicação sobre as diferenças das pessoas com deficiência (ou então, uma comunicação apenas de sentido médico) dos sistemas político e jurídico, em relação aos demais, teve um significado social de exclusão. Contudo, ao serem declarados politicamente (por procedimento de Emenda Constitucional) como direitos fundamentais na ordem constitucional brasileira, criaram-se condições de possibilidade para comunicação mais efetiva dos seus direitos. A instrumentalização pela política, tanto do texto constitucional quanto do pacto internacional (Convenção sobre Direitos das Pessoas com Deficiência), fez com que esta comunicasse (e reconhecesse) acerca da diferença das pessoas nestas condições para que sobre elas se possam declarar direitos.

Sendo assim, pode-se dizer que a hipótese inicial - de que a teoria dos sistemas autopoiéticos parte da diferença (e não da igualdade) daquilo que signifique o humano em sociedade, e de que isto auxilie na observação da inclusão dos excluídos nos sistemas sociais - é confirmada. Porém, deve-se observar que, por mais que as condições sintáticas e semânticas para a inclusão da pessoa com deficiência estejam criadas para a atuação dos sistemas da Política e do Direito no sentido de comunicar acerca deste grupo social tradicionalmente excluído, é importante considerar que, pragmaticamente, a sua inclusão é um 
problema complexo. Para além das comunicações políticas (normas gerais) acerca da inclusão; para além da inserção de novos postulados normativos no programa jurídico brasileiro (a serem interpretadas e julgadas pelos Tribunais e juízes); é necessário que outros sistemas (Economia, Ciência, Tecnologia, etc.) também sigam comunicando acerca do problema da deficiência (física e mental) não apenas como um problema médico (inclusão após cura), uma externalidade econômica ou fonte de lucratividade. Mas estas questões, conforme a teoria dos sistemas autopoiéticos permite concluir, se reportam à autorreferência dos demais sistemas, não sendo nem o Direito, nem a Política, capazes de se imiscuírem nas operações dos demais sistemas senão pela via reflexiva.

\section{REFERÊNCIAS}

IZUZQUIZA OTERO, Ignacio. La sociedad sin hombres: Niklas Luhmann o la teoría como escándalo. Barcelona: Anthropos, 1990.

LUHMANN, Niklas. Complexity and meaning. In Essays on self-reference. New York: Columbia University Press, 1990.

El derecho de la sociedad. Tradução para o espanhol de Javier Torres Nafarrate, com colaboração de Brunhilde Erker, Silvia Pappe e Luis Felipe Segura. 2. ed. Cidade do México: Herder, Universidad Iberoamericana, 2005.

Introdução à teoria dos sistemas. Tradução de Ana Cristina Arantes Nasser. 2. ed. Petrópolis, RJ: Vozes, 2010.

- La ciencia de la sociedad. Traducción de Silvia Pappe, Brunhilde Erker, Luis Felipe Segura; sob direção de Javier Torres Nafarrate. México: Universidad Iberoamericana; ITESO; Anthropos, 1996a.

La costituzione come acquisizione evolutiva. In: ZAGREBELSKY, Gustavo; PORTINARO, Pier Paolo; LUTHER, Jorg. Il Futuro dela Costituzione. Torino: Einaudi, $1996 \mathrm{~b}$.

La sociedad de la sociedad. Tradução para o espanhol de Javier Torres Nafarrate. México: Editorial Herder, 2007.

Law as a social system. Tradução para o inglês de Klaus A. Ziegert. New York: Oxford University Press, 2004.

Los derechos fundamentales como institución: aportación a la sociología política. Tradução para o espanhol de Javier Torres Nafarrate. México: Universidad Iberoamericana, 2010.

Meaning as sociology's basic concept. In . Essays on self-reference. New York: Columbia University Press, 1990.

Poder. Tradução de Martine Creusot de Rezende Martins. Brasília: Editora Universidade de Brasília, 1985. 
. Sistemas sociales: lineamientos para unateoría general. Tradução para o espanhol de

Silvia Pappe e Brunhilde Erker; Coordenação de Javier Torres Nafarrate. México: Allianza Editorial/Universidad Iberoamericana, 1991.

Sociologia do Direito I. Rio de Janeiro: Tempo Brasileiro, 1983.

The autopoiesis of social systems. In Essays on self reference. New York:

Columbia University Press, 1990.

The self-reprodution of Law and its limits. In Essays on self reference.

New York: Columbia University Press, 1990.

; DE GIORGI, Rafaelle. Teoria della società. 8. ed. Milano: Franco Angeli, 1996.

MAGALHÃES, Juliana Neuenschwander. O paradoxo dos direitos humanos. Revista da Faculdade de Direito - UFPR, Curitiba, n.47, p.29-64, 2008.

MANSILLA, Dario Rodriguez; NAFARRATE, Javier Torres. Autopoiesis, la unidad de una diferencia: Luhmann y Maturana. Sociologias, Porto Alegre, ano 5, p. 113-113, jan.-jun. 2003.

NEVES, Marcelo. A força simbólica dos direitos humanos. In Revista Eletrônica de Direito do Estado, n. 4. Salvador, Bahia, Brasil: outubro/novembro/dezembro de 2005.

Transconstitucionalismo. São Paulo: Editora WMF Martins Fontes, 2009.

ROCHA, Leonel Severo. Da epistemologia jurídica normativista ao construtivismo sistêmico. In __ (Org.). Introdução à teoria autopoiética do sistema do Direito. 2. ed. rev. amp. Porto Alegre: Livraria do Advogado Editora, 2013.

Três Matrizes da Teoria Jurídica. Constituição, Sistemas Sociais e Hermenêutica: Programa de Pós-Graduação em Direito da UNISINOS: mestrado e doutorado, Porto Alegre; São Leopoldo, p. 121-136, 1999.

SISTEMA SOCIAL. In: BARALDI, Claudio. Sentido. In CORSI, Giancarlo. ESPOSITO, Elena. BARALDI, Claudio. Glosario sobre la teoría social de Niklas Luhmann. Tradução de Miguel Romero Perez, Carlos Víllalobos (sob direção de Javier Torres Nafarrate). México: Universidade Iberoamericana; Guadalajara: ITESO; Barcelona: Anthropos, 1996.

VILLAS BÔAS FILHO, Orlando. Teoria dos Sistemas e o Direito Brasileiro. São Paulo: Saraiva, 2009. 